NOTAS

\title{
ARISTÓTELES HOY
} Jorge Serrano*

$\mathbf{E}_{\mathrm{n}}$ versario de la muerte de Aristóteles, la UNESCO organizó un coloquio que reunió a diversos especialistas - expositores y críticos - de la obra de célebre filósofo griego, que estuvo compuesto por dos partes claramente diferenciadas: la primera de Estudios y la segunda, una mesa redonda integrada tripartitamente por Lógica y lenguaje; Las ciencias; la Filosofía. La

92 obra que aquí comento, ${ }^{* *}$ producto de este homenaje, está precedida por un prefacio algo extenso a cargo de su organizador, M.A. Sinaceur y de tres testimonios: el de George Kreisel, miembro de la Royal Society of the United Kingdom; otro de Jean Dausset, profesor del Collège de France; y por último el de Jacques Lacan, restaurador de los estudios freudianos, lamentablemente fallecido en 1981.

En el corazón del edificio construido en honor de la razón, la obra de Aristóteles se levanta como un árbol

* Departamento Académico de Estudios Generales, ITAM.

** Aristote aujourd'hui, 1988, 2a., Ed. Érès. maestro. La inmensidad del dominio por él reunido, junto con estudios sobre diferentes puntos sugería el homenaje a esa fuerza meditativa que en la actualidad aún nos interroga.

Comentar adecuadamente este Coloquio parece una tarea imposible, dada la cuidadosa selección de sus ponentes, todos de gran calidad, tanto del mundo occidental como de Oriente, pero no obstante trataré al menos de dar cuenta de algunas de las memorias publicadas, destacando las que más poderosamente me llamaron la atención.

En la sección dedicada a Aristóteles y la educación se señala: "Conocemos al Aristóteles investigador, al fundador de diversas disciplinas, al lógico impecable, al filósofo, al 'maestro de los que saben', pero conocemos mal al Aristóteles educador." Este juicio de H.I. Marrou será compartido por muchos, como C. Hummel, que no obstante reconoce: "Aristóteles se consagró tanto a la enseñanza como a la investigación. Él es el prototipo del professor. La parte de su obra que nos ha transmitido a través de los veintitrés siglos constituye su obra pedagógica, en ella encontramos los 'cursos' que Aristóteles imparte." 
Si bien Aristóteles realizó una obra puramente académica, llegó a ser un privat-docent y en sus escritos encontramos uno de los aforismos más notables de la literatura pedagógica universal, suficiente para mostrarnos su profundo interés en la materia. Su reiterada afirmación de que "es imposible pensar sin imágenes", 1 frecuentemente entendida sólo como una tesis de su teoría del conocimiento, sin duda tiene una serie de derivaciones de orden pedagógico de inusitado valor, máxime si tomamos en cuentala época de su formulación.

Para Aristóteles la finalidad de la educación es idéntica a la del hombre. Evidentemente toda educación apunta al ideal humano, pero para el discípulo de Platón ésta resulta indispensable para la actualización del hombre, que aspira como bien supremo a la felicidad. Ahora bien, el hombre feliz de Aristóteles no es el "salvaje natural" sino el "hombre educado". El hombre feliz, el hombre de bien es virtuoso y la virtud se adquiere por la educación. Ética y educación se confunden; los libros de Aristóteles sobre ética resultan manuales que enseñan el arte de vivir.

Sabemos poco sobre el educador que fuera de Alejandro, sin embargo iqué conjunción más extraordinaria! Jacob Burckhardt estimaba que fue gracias a la educación de Alejandro que Aristóteles alcanzó su mayor in-

${ }^{1}$ Aristóteles, "De anima", III, 7, 431a, 16; y "De la memoria y de la reminiscencia", 449 b, 31 . fluencia sobre la historia; y un escritor moderno se refiere con estos términos a dicho encuentro: "Aristóteles, este hombre que construyó con sus pensamientos un recinto tan vasto que la ciencia occidental pudo habitarlo durante dosmil años, contribuyó con sus ideas que inculcó a Alejandro a crear las condiciones necesarias para la realización de este mismo Occidente. Sin Alejandro apenas conoceríamos el nombre de Aristóteles. Sin Aristóteles nunca hubiera llegado Alejandro a ser el Alejandro que todos conocemos." 2

Sabemos que Aristóteles fundó el Liceo, pero poco conocemos de la manera de administrarlo desde el punto de vista de lo que hoy llamaríamos académico. La investigación complementaba la educación "superior". En la mañana tenía lugar la enseñanza para los alumnos inscritos, mientras que por la tarde se encontraba abierta a un público más extenso - como si se tratara de una escuela popular. Parece que Aristóteles confiaba la dirección del Liceo a todos los miembros del cuerpo magisterial, rotando a cada uno luego de diez días de asumir esta responsabilidad: ${ }^{3}$ ¿Preludio de una democratización de la enseñanza?

El cuidado pedagógico, la dimensión educativa se encuentran a todo lo largo y ancho de la obra del estagirita. Un día habrá que analizar el proceso pedagógico tal como aparece estructurado en sus escritos, donde pode-

\footnotetext{
${ }^{2}$ Peter Baum, Alexander oder die Verwandlung der Welte, Gesammelte Werke, p. 411.

${ }^{3}$ D. Ross, Aristotle, p. 7.
} 
NOTAS

mos apreciar su característica manera de plantear los problemas desde diferentes ángulos, para discutirlos como auscultándolos.

En el texto "Acerca de la lógica", de Georg Kreisel, encontramos análisis sobre aspectos que si bien en Aristóteles apenas aparecen esbozados anticipan una parte de la lógica contemporánea - o filosofía de la matemática - : el intuicionismo de Hilbert. En este dominio, además de que Aristóteles escribió de manera fragmentaria, buena parte de su obra se extravió, por lo que sus primeros lectores jamás cayeron en la cuenta de que se trataban de temas lógicos, que apenas serían comprendidos muchos siglos después, con la creación de la lógica axiomática. Muchos de los asuntos abordados por esta disciplina por cierto ya habían sido estudiados por el estagirita al tratar las nociones de "infinito", "prueba", "anteriormente conocido" " "probabilidad", como señala el autor del texto que comento. De pasada señalo un enunciado de Aristóteles que conserva extraordinaria actualidad: "Los matemáticos no tienen ninguna necesidad del infinito y no lo utilizan; en realidad ellos sólo tienen necesidad de un 'fragmento' finito; eso sí, que sea tan grande como se necesite tenerlo."

También Kreisel se pregunta porqué resulta fascinante el pasaje de su Lógica donde Aristóteles se pregunta sobre las demostraciones generales y particulares. ¿Acaso el estudio general de las pruebas forma parte de la lógica y es un objeto de moda? Si bien no todo su contenido se inicia con Aristóteles, dicho pasaje resulta extraordinariamente actual en la llamada lógica formal. Y desde un registro más discutible señalaría que en todo matemático duerme un artista deseoso de cincelar y pulimentar indefinidamente sus demostraciones, examinando todas sus variantes. El pasaje de Aristóteles muestra un criterio simple - casi "bourbakiano" - para escoger de entre diversas demostraciones, la mejor.

Igualmente sagaz encuentro las relaciones que Hans-Jürgen Treder establece entre las respectivas investigaciones sobre el movimiento, mostrando que la física aristotélica, despreciada por gran parte de los posgalileanos se encuentra más próxima a la concepción de Einstein que a la de Newton.

Veamos un ejemplo: "La definición aristotélica de los 'movimientos propiamente dichos' se encuentra determinada por la comprehensión de las aplicaciones del axioma del movimiento peripatético. Según Aristóteles, un barco $B$ llevado por una corriente $F$ se encuentra, propiamente hablando, en estado de reposo; solamente si el barco se mueve con relación a la corriente se puede decir que existe un 'verdadero movimiento' con una velocidad relativa $w$ con relación a la corriente. Ciertamente, la corriente del río $F$ que transcurre constituye un estado de movimiento verdadero $X$ con relación al río $U$, pero, el barco no posee, con respecto a la ribera del río ningún punto en común y, por consiguiente, no se encuentra animado de ningún movi- 
mientoverdadero con relación a aquélla. Tal movimiento - en el lenguaje de Aristóteles - no es sino accidental. Apreciamos de esta manera, empleando el lenguaje contemporáneo, que la peripatética de ninguna manera es una física ingenua y propia del sentido común - tomando éste en su peor acepción-; conserva una posición muy interesante en relación con la relatividad del lugar y del movimiento."

No quiero señalar con esto que Aristóteles es un relativista avant la lettre en el sentido einsteniano del término; en efecto, "desde el punto de vista dinámico, habida cuenta del 'principio de razón suficiente', en Aristóteles no existe ningún principio de relatividad, ya que todo movimiento, todo cambio de lugar, exige la presencia de una fuerza, en tanto que causa".

"Pero, no debemos perder de vista que el lugar de un cuerpo es definido por Aristóteles de manera estrictamente local y, por consiguiente, relativa: el lugar es la "superficie de delimitación" del cuerpo con relación a la materia que lo rodea o circunscribe. Un cambio de lugar significa, según Aristóteles, un cambio de esta superficie de delimitación, permaneciendo la forma incambiable. Además, "en el cosmos de Aristóteles existe una determinación del lugar global per distantiam que resulta de la relación con el límite externo - este mismo sin lugar - del cosmos: la esfera de las estrellas fijas. $\mathrm{Y}$ es también en relación a este cielo

${ }^{4}$ Aristote aujourd'hui, p. 113-4. que son definidos físicamente los lugares y los movimientos naturales de los cuerpos. Es por otra parte, desde Huygens y Leibniz, desde Mach a Einstein, hacia donde tiende la astronomía contemporánea y que se encuentra formulado en lo que podríamos llamar aquí el 'principio de Huygens-Mach', la 'doctrina de Mach-Einstein"'5 "De esta manera, la teoría aristotélica del espacio y del movimiento esclarece las teorías correspondientes a la física contemporáneay, en particular, la teoría de la relatividad. La ley aristotélica del movimiento no implica ninguna 'invarianza cinemática' en el sentido de los movimientos 'inerciales' galileanos. El principio dinámico en Aristóteles conduce a los movimientos 'absolutos' en la medida en que cada movimiento tiene una 'causa'. Pero, el carácter estrictamente local de los conceptos de lugar y de velocidad implica la existencia de un nexo relativista entre todo movimiento y su medio. Esto se aplica al 'espacio topológico' de Aristóteles." 6

En otra ponencia acerca de la Físi$c a$ de Aristóteles, Gérard Verbeke indica "el azar y la fortuna intervienen en los acontecimientos que ocurren en el mundo, pero a título secundario y subordinado: ellos son causas accidentales de eventos poco frecuentes, que se producen con vistas a un fin".? Se trate de acontecimientos naturales o de actos libres, excepcionalmente

\footnotetext{
${ }^{5} I$ Ibid., p. 121.

${ }^{6}$ Ibid.

${ }^{7}$ Phys. II, 5, 197b, 5-7.
} 
NOTAS

ocurre que el resultado no se sitúa en la línea de lo que normalmente se alcanzaría. A los ojos de Aristóteles lo que se produce gracias al azar y a la fortuna no puede concebirse como un acontecimiento sin causa, sino que ésta permanece indeterminada. Curiosamente es la misma postura que Einstein sostuvo hasta el fin de su vida, pues pensaba que el azar no existía, entendiendo por esto que los acontecimientos pudieran ocurrir sin la intervención de una causa. "Dios no juega a los dados con el universo", era su ocurrente y frecuente respuesta.

¿Quedaría con esto descartada la teleología universal? se pregunta Verbeke. La respuesta de Aristóteles sería: no - si bien sería necesario matizar. Esta teleología no conduce a un determinismo rígido, sino que existe la contingencia tanto en los actos libres como en los de la naturaleza animada e inanimada. La ley de la finalidad rige en el mundo entero - el que conoció Aristóteles - sin excluir los acontecimientos que no alcanzan el fin al que se hallaban orientados; justamente las excepciones confirman la regla.

Todas estas notas que buscan demasiado simplemente su traducción a cuestionamientos contemporáneos muestran que aquí Aristóteles sólo sirve de pretexto, señala otro de los ponentes, Marc Lévy-Leblond. ¿No podría ser distinta esta conmemoración que linda en lo ridículo? La ocasión resulta única para celebrar en Aristóteles la unidad del saber, la universalidad de la ciencia, la ética del conocimiento en un mundo donde la ciencia ha dividido, jerarquizado y explotado. De nada sirve invocar una pluridisciplinariedad que no es recomposición de saberes parcelarios sino mera yuxtaposición - y este Coloquio es muestra de ello- que podemos lamentar pero es imposible negar. Entonces no nos escondamos tras la estatua de Aristóteles y unámonos para la "restauración de los monumentos antiguos". 8

Entre los penetrantes análisis que cierran el volumen que comentamos, se encuentra el de Pierre Aubenque - uno de los más notables especialistas en Aristóteles - que se cuestiona, qué puede decirnos este filósofo dosmil trescientos años después, para responderse que existe más de una respuesta, siendo la primera un hecho que, por demasiado evidente, suele pasar inadvertido. Esta respuesta fáctica consistiría en mostrar todo lo que nuestra civilización tiene de positivo - sin olvidar los aspectos discutibles - debido al pensamiento de Aristóteles. Nuestra lógica, nuestra gramática y aún nuestra ciencia han tomado a tal grado de él sus reglas, axiomas y conceptos, que somos aristotélicos sin saberlo - un poco como M. Jourdain hacía prosa.

Pero no siempre las identificaciones de la presencia de Aristóteles que realiza este erudito resultan propiamente laudatorias. Por ejemplo, indicará que no son el sentido común o la naturaleza de la inteligencia los que

${ }^{8}$ Aristote aujourd'hui, p. 318. 
dictan a Aristóteles el contenido de su filosofía, sino que es él mismo quien sobre las posibilidades que le presenta su pensamiento toma decisiones que durante siglos serán el canon de toda ciencia, las condiciones de posibilidad de toda organización de la experiencia, los presupuestos de todo diálogo entre los hombres y de toda la vida social reglamentada.

Entre estas "decisiones" fundamentales aristotélicas podemos hallar: la enunciación clara del principio de no contradicción - que Aristóteles llama principio del más fuerte - junto al del tercio excluido; el principio de continuidad; el establecimiento de una serie de categorías que organizan la percepción del mundo y que han permitido la distinción entre las diferentes ciencias; el primado atribuido a la noción de ser como horizonte universal de toda comunicación y de toda comprehensión, el principio 'teleológico' según el cual la naturaleza actúa hacia fines que le son inmanentes; la afirmación que señala que entre todos los entes existe uno, el divino, que al mismo tiempo posee un valor ejemplar y un poder causal universal, respecto del cual desde entonces se postula que es fundamental y fundador.

Estas proposiciones forman entre sí una estructura que Heidegger no ha dudado en llamar onto-teo-logía (o mejor, onto-teo-lógica), que a través de la metafísica derivada ha determinado durante siglos el modo de pensar del hombre occidental, y también ha influido en el de Oriente. Durante la Edad Media el aristotelismo frenó el desarrollo de la ciencia (en particular de la física-matemática) y permanecerá en las simplificaciones y organización de la estructura onto-teológica de la metafísica, cuyos racionalismo y objetivación en el inicio de los tiempos modernos no favorecieron el mejor desarrollo de las formas de pensamiento tanto científico como técnico.

Ante las consecuencias deshumanizantes de los "añadidos" de este sistema metafísico logocéntrico dominante por siglos, que reduce el ser a la "representatividad" y la "calculabilidad", muchos pensadores proponen evitarlo y aún destruirlo - o en todo caso "descontruirlo". Pero ciertamente este proyecto suena arbitrario y absurdo, pues la sistematización aristotélica descansa sobre un conjunto de proposiciones respecto de las cuales simplemente no se puede decir que sean verdaderas o falsas, dado que será a partir de ellas que se determinen la definición y los criterios de verdad y de verificabilidad. En este sentido, piensa Aubenque, la metafísica escapa al reproche neopositivista según el cual ésta estaría constituida por proposiciones inverificables $y$, por consiguiente, desprovistas de sentido. La objeción daría en el blanco si cuestionara su pretensión de validez absoluta, que al mismo tiempo pondría en juego la comparación con otros sistemas de pensamiento no aristotélicos, no occidentales, que fundados sobre otras bases no resultan menos coherentes y operatorios.

En todo caso el genio de Aristóteles ha experimentado un desarrollo ex- 


\section{NOTAS}

traordinario al punto de que si hoy no podemos considerarlo "el maestro de los que saben", incuestionablemente permanece como el maestro inigualado en lucidez y vigilancia conceptual. 